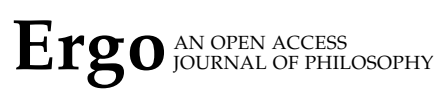

\title{
On Persistence in Aristotle
}

\author{
SCOTT O'CONNOR \\ New Jersey City University
}

\begin{abstract}
In the Categories, Aristotle claims that the most distinctive mark of substance is that it persists through change of contraries (4a10-11), a claim he explains elsewhere by appeal to hylomorphism. This explanation has been characterized as an answer to what I call the Conditions Question, a question that asks for the conditions under which a substance before and after a change are identical. The evidence that Aristotle uses hylomorphism to answer this question is inconclusive, I argue. But I argue that Aristotle does use hylomorphism to answer a different question about persistence, a question that asks why substances are not destroyed as they change. I call this the Survival Question, and I argue that Aristotle's answer to it does not entail an answer to the Conditions Question; Aristotle can consistently explain why substances are not destroyed as they admit contraries without being committed to any view about what, if anything, identity through time for substances consists in.
\end{abstract}

\section{Introduction}

In the Categories, Aristotle claims that "It seems most distinctive of substance that what is numerically one and the same is able to receive contraries" (4a10-11). ${ }^{1}$ For example, Flipper, the friendly dolphin, remains numerically one and the same as he changes from being cold to being warm. Given that such an ability is unique to substance, we might expect Aristotle to explain it. ${ }^{2}$ How can Flipper remain numerically one and the same as he changes? Aristotle offers no explanation in the Categories, but he does offer an explanation in his mature metaphysics and

Contact: Scott O'Connor <soconnor@njcu.edu>

1. Unless otherwise noted, all translations are from Barnes (1984).

2. I restrict my use of 'substance' throughout to individual hylomorphic compounds that have internal principles of change and stability, e.g., dolphins, oak trees, etc. Artifacts are not substances on this use of the word, but I do occasionally use artifacts to illustrate various features of Aristotle's hylomorphism. Masses are also not substances on this use of the word, and I do not discuss Aristotle's views, if any, about the persistence of masses. 
natural treatises by appealing to hylomorphism. For instance, in On Generation and Corruption 1.5 he claims that a growing substance requires the persistence of its ousia (321a34-35), a remark that is explained earlier in GC 1.2 with the claim that a substance is destroyed by the destruction of its form and matter (317a20-27). Flipper's persistence, then, requires Flipper to be a hylomorphic compound.

How exactly are we to understand this requirement? There are several questions we can ask about how Flipper remains numerically one and the same as he admits contraries, and I am interested in which question Aristotle uses hylomorphism to answer. One question is what Flipper's identity through time consists in, a question about why the warm dolphin is identical to the cold dolphin from earlier. Answering this question requires identifying the conditions under which such an identity holds. Call this the Conditions Question. A different question is why Flipper is not destroyed as he warms up, a question about why a substance is destroyed by some changes and not others. Answering this question requires explaining why warming up, as opposed to, say, moving onto land, does not kill dolphins. Call this the Survival Question. The answers to these two questions can come apart, or so I argue (Section 8). ${ }^{3}$

Aristotle never explicitly characterizes the question he wants to answer, making it as difficult to identify the explananda in his explanations of persistence as it is to understand the explanantia. But many think that his attempts to explain persistence are best characterized as answers to the Conditions Question. On this view, Aristotle believes that the hot and cold dolphins are identical just if they satisfy the criterion of identity for dolphins. Debate has centered on two questions. The first is how hylomorphism figures in these criteria. Are they specified in terms of sameness of matter (or spatiotemporal continuity of matter ${ }^{4}$ ), or in terms of sameness of form ${ }^{5}$ The second is whether Aristotle's apparent appeal to form or matter to answer the Conditions Question affects his understanding of either. For instance, Jennifer Whiting (1986) has argued that identity through time for substances consists in sameness of form, and she has argued that this requires the forms of co-specific individuals to be numerically distinct from one another.

Less has been written about the Survival Question, but the following would be

3. There are other questions about persistence. For instance, how do species persist? What is the correct ontology of persisting objects, and, in particular, do persisting objects have temporal parts? Some think that Aristotle has a stake in this latter debate. See Code (1976a), Code (1976b), Matthews 1982: 1992), and Bowin (2008). My focus is how substances remain numerically one and the same as they admit contraries. By claiming that Aristotle's explanation of how substances can do this is best characterized as an answer to the Survival Question, I do not mean that the Survival Question is the only question about persistence that interests Aristotle. I would like to thank David Charles for pressing me on this point.

4. See, e.g., Code (1978).

5. See Anscombe (1953), Charlton (1972), Cohen (1984), Frede (1987), Furth (1978), Hartman 1977), Lloyd (1970), Popper (1953), Whiting (1986), and Zeller [1897 83-96). 
uncontroversial: ${ }^{6}$ Aristotle believes that "it is impossible for a thing still to remain the same if it is entirely transferred out of its species, just as the same animal could not at one time be, and at another not be, a man" (Top. 4.5, 125b35-39). Thus, in order for a substance to remain numerically one and the same as it admits contraries, it must remain an $\mathrm{F}$, where ' $\mathrm{F}$ ' is the name of the kind it belongs to. ${ }^{7}$ For instance, Flipper must remain a dolphin as he warms up if he is to survive. Since, for Aristotle, kinds are individuated by what they can do, a persisting substance must maintain the capacities to do the characteristic things that members of its kind can do. Interpreters would agree that Aristotle explains how substances maintain kind-specific capacities as they change by appealing to hylomorphism, though the exact nature of this appeal would not be agreed upon.

While interpreters would agree that Aristotle appeals to hylomorphism to explain how substances retain their kind-specific capacities as they admit contraries, I am unaware of anyone who thinks that this appeal does not answer the Conditions Question. But I think this mischaracterizes the explananda in Aristotle's attempt to explain how substances remain numerically one and the same as they admit contraries for the following reasons: ( 1 ) the evidence that Aristotle is committed to an answer to the Conditions Question is inconclusive, (2) the evidence that he does raise and answer the Survival Question is conclusive, and (3) his answer to the Survival Question entails no answer to the Conditions Question.

I argue for (1) by explaining the conditions for an adequate criterion of identity (Section 2) and arguing that nothing Aristotle explicitly says about persistence entails such a criterion (Sections 3-4). My argument is not that he never asks the Conditions Question; interpreters would agree that Aristotle does not explicitly ask this question. My argument is that nothing he says about persistence entails an answer to it. I argue for (2) by distinguishing the Survival from the Conditions Question (Section 5) and sketching Aristotle's answer to the Survival Question (Sections 6-7)-a sketch because my goal is to characterize this question and not to defend an exhaustive interpretation of Aristotle's answer to it. I argue for (3) in Section 8 by showing how Aristotle's answer to the Survival Question is

6. Some have identified explanations of persistence that are best characterized as answering the Survival Question. Gad Freudenthal discusses two related questions. First, given that the constituents of a composite substance are opposites (elements or powers) that attempt to dominate one another, "what keeps within these substances a constant equilibrium so that the form defining each substance remains the same?" (1995:182). Second, why do the elements of a substance not travel to their natural places, thereby destroying the substance? He offers a lengthy account of the roles that form and heat play in answering both questions. Mary Louise Gill also discusses these questions and identifies what she considers a cause of persistence for Aristotle (1991 Chapter 7). While this paper is on a par with the answer Gill and Freudenthal identify, its main aim is to properly characterize the question that this answer is an answer to.

7. I assume that, for Aristotle, infimae species are kinds like human, dolphin, etc. A term ' $\mathrm{F}$ ' is a kind term just if ' $F$ ' is the name for some infima species. 
compatible with there being no criteria of identity at all.

\section{The Conditions Question}

Answering the Conditions Question requires identifying a diachronic criterion of identity for substances. Several interpreters have argued that, for Aristotle, the relevant criterion is determined by the sort of thing a substance is. David Bostock explains this view as follows:

... any such thing [a persisting substance] must be of a definite sort, so that there is some sortal noun ' $\mathrm{A}$ ', which in someway embodies its criterion of identity over time. The item can then be referred to as 'this $A^{\prime}$, and later as 'the same $\mathrm{A}^{\prime}$ ', where we do understand what it is for this $A$ and that A to be (over time) the same A. In Aristotelian terms, then, being an A would be, or would be part of, the essence of As. So it is the thing's essence that supplies its criterion of identity over time, and thus enables it to be a substance. Hence what has no essence cannot be a substance. (2006. 35$)^{8}$

Call the view that what makes the referents of some sortal noun identical is that they satisfy the criterion of identity associated with that sortal Criterialism. ${ }^{9}$ Determining whether Aristotle is committed to Criterialism requires having a clear characterization of it in view. Two observations will suffice:

Observation 1: Criterialism claims that the criterion of identity for a being depends on the kind it belongs to. A criterion of identity states individually necessary and jointly sufficient conditions for an identity to hold. ${ }^{10}$ They have the following standard form:

For any $x$, for any $y$, if $x$ is an $\mathrm{F}$ and $y$ is an $\mathrm{F}$, then $x=y$ iff $\mathrm{R} x y .{ }^{11}$

8. Montgomery Furth explains the view in the following way: "the predicates naming the substantial kinds are individuative predicates, in the sense of terms marking off objects severally by way of a criterion of individuation that is part of their meaning" (1988 30).

9. Criterialism was first explicitly defended by Locke (1979 Book II, Chapter xxvii), who claimed that what identity consists in for things of one sort may differ for things of a different sort.

10. They are most famously associated with Gottlob Frege, who claimed, "If we are to use the symbol $a$ to signify an object, we must have a criterion for deciding in all cases whether $b$ is the same as $a$, even if it is not always in our power to apply this criterion" (1884 73).

11. This is a one-level criterion of identity. In a one-level criterion, the analysans mentions (or quantifies over) those entities in the analysandum for which the criterion is being specified. For instance, a criterion of identity for persons in terms of souls mentions 'persons' in the analysans: person A is identical to person B iff the soul of person A is identical to the soul of 
' $\mathrm{F}$ ' is a general term that specifies the relation that $x$ and $y$ must stand in if they are to be identical. Not every general term specifies such a relation. 'Daughter' and 'pale' do not, but it is a point of controversy which do. ${ }^{12}$ For our purposes, we need only observe that those entities whose identity is in question must fall under some general term that specifies a criterion for their identity to hold. An example for sets:

For any $x$, for any $y$, if $x$ is a set and $y$ is a set, then $x=y$ iff $x$ and $y$ have the same members.

This criterion states that the identity of sets consists in their having the same members. This differs from the criterion of identity for houses, which might state that houses $x$ and $y$ are identical iff they have the same property deeds. Here the identity of houses consists not in having the same members but in having the same property deeds.

These examples are examples of synchronic criteria of identity; they make no mention of time. Criteria of identity over time-diachronic criteria of identitystate what the identity through time for some being consists in. An example for persons:

For any $x$, for any $y$, if $x$ is a person and $y$ is a person, then $x$ at $\mathrm{t} 1=y$ at $\mathrm{tn}$ iff $y$ is psychologically continuous with $x$.

Consider Socrates's trial and subsequent imprisonment. This criterion entails that the defendant charged with corrupting the youth of Athens is identical to the prisoner who debates whether it is just to escape prison iff the prisoner and defendant are psychologically continuous, for example, iff the prisoner has memories of the defendant's experiences. ${ }^{13}$

Observation 2: The claim that the identity through time of a being consists in the satisfaction of certain conditions is stronger than the claim that an identity holds if and only if certain conditions are satisfied. The former claim is a claim

person B. In contrast, the analysans of a two-level criterion of identity makes no mention of those entities whose identity is in question. Frege offered one example: the direction of line $a$ is identical to the direction of line $b$ iff line $a$ is parallel to line $b$. Here we have a criterion of identity for directions that makes no mention of 'direction' in the analysans. There is some debate as to whether one-level criteria can be re-formulated as two-level criteria, and vice versa. There is also some debate over which should be preferred. See Lowe $(1989.5-7 ; 1991)$ and Williamson (1990). I do not know of any interpreter of Aristotle who discusses the issue, so I will feel free to use both levels when characterizing the various criteria attributed to him.

12. Hirsch (1982, 36) and Wiggins 2001, 22) stipulate that a term ' $F$ ' is a sortal if ' $F$ ' embodies a criterion of identity for Fs. On this approach, sortals are identified by first identifying criteria of identity and then identifying which general terms embody these criteria.

13. See Shoemaker and Swinburne (1984) for discussion of psychological continuity. 
about the explanation for an identity holding. The latter is not. For instance, the claim that the defendant and prisoner are identical iff they are psychologically continuous is different from the claim that they are identical because they are psychologically continuous. The bi-conditional claim is neutral with respect to explanatory direction; it is compatible with the claim that our defendant and prisoner are psychologically continuous because they are identical persons, and it is compatible with the claim that they are identical persons because they are psychologically continuous.

The same point is often made by saying that a criterion of identity must not merely state necessary and sufficient conditions for an identity to hold, but also that these conditions must be non-circular and informative. The conditions are circular if the criterion of identity for those entities stated in the analysans are given in terms of those stated in the analysandum. Suppose, for instance, that a philosopher claimed that sameness of person consists in sameness of soul and that sameness of soul consists in being possessed by the same person. Having the same soul will not then be an adequate criterion of identity for persons: while having the same soul is both a necessary and sufficient condition for our defendant and prisoner to be identical, it is circular because sameness of soul itself consists in the sameness of person. The conditions are informative, on the other hand, only if they do not presuppose what they are criteria of. Suppose, for example, one offered the following as a criterion of identity for persons:

For any $x$, for any $y$, if $x$ is a person and $y$ is a person, then $x=y$ iff there is some person $z$ such that $x=z$ and $y=z$.

Perhaps this might tempt one if one thought that being identical to the teacher of Plato is a necessary and sufficient condition for our defendant and prisoner to be identical with one another. Each is identical to that teacher, and since identity is transitive, they are identical to one another. However, the analysans of this supposed criterion presupposes what it is meant to be a criterion of, that is, it presupposes a criterion of identity for persons; the defendant and teacher of Plato are themselves identical only if they satisfy the criterion of identity for persons. So, to say that identity for persons consists in being identical to some person is not informative at all. (For convenience, in what follows, I will use ' $\because$ ' to formulate criteria that are supposedly non-circular and informative as well as being necessary and sufficient for an identity to hold. ${ }^{14}$ )

If Aristotle is committed to an answer to the Conditions Question, he is committed to there being criteria that satisfy these conditions. What evidence is there that he is so committed? His denial that a substance can, as Montgomery Furth (1978) puts it, migrate out of its species is insufficient evidence. Aristotle

14. See Lowe 2009 23-24).

Ergo $\cdot$ vol. 5, no. $20 \cdot 2018$ 
does deny this. In Physics 1.7, he illustrates some general features of change by claiming that a human persists and remains human as she becomes musical (190a9-11). This example illustrates two claims. First, the subject of a change persists while the privation does not (see 190a14-22). ${ }^{15}$ Second, the subject remains the same kind of thing throughout the change. ${ }^{16}$ But these two claims are not sufficient evidence for Criterialism: there are different reasons why a philosopher might claim that Socrates remains human as he learns music, and Criterialism is only one of them. (Another reason might be that being human is an essential but non-individuating feature of Socrates.)

What is sufficient evidence? If Aristotle thinks that some predicates embody criteria of identity over time, we might expect him to specify these criteria. If he meets this expectation, then this is sufficient evidence that he accepts Criterialism. Some believe that he meets the expectation by claiming that the warm dolphin is identical to the colder dolphin from earlier because their matter is identical (or spatiotemporally continuous). Others have claimed that they are identical because they have the same form. ${ }^{17}$ If Aristotle does accept any of these proposed criteria, then he is committed to Criterialism.

But I argue that the evidence is inconclusive as to whether Aristotle does provide criteria of these sort, and so I conclude that it is inconclusive as to whether he is committed to Criterialism. My arguments rely on the following principle of charity: since Aristotle does not explicitly ask the Conditions Question, we should only attribute to him an inadequate answer to it if his explicit statements entail an inadequate answer. I argue that the criteria of identity that have been attributed to Aristotle are inadequate, and I argue that the texts in which these criteria are found do not entail them; there are plausible reconstructions of the texts that do not leave Aristotle with a poor answer to a question he never asks.

\section{Matter}

Our first interpretation says that Aristotle believes that identity through time for substances consists in sameness of matter:

(A) For any $x$, for any $y$, if $x$ is a substance and $y$ is a substance, then $x$ at $\mathrm{t} 1=y$

15. While Aristotle begins the chapter by claiming he will speak generally about change (189b30-33), some argue that he restricts his claims about persistence to qualified change. Even if he does so restrict it, there remains the question of how substances persist through qualified changes, the topic of this paper. For further discussion, see Charlton (1970, 1992), Code (1976b), Jones (1974), and $\mathrm{O}^{\prime}$ Connor (2015).

16. Taking this example as evidence of Criterialism, Sarah Waterlow thinks that there is a description of each subject that is "a covering concept under which 'they' [the subject before and after the change] are the same individual" 1982 47). I take Waterlow's 'covering concept' and Bostock's 'sortal' to be equivalent.

17. See Footnote 5 for references. 
at $\operatorname{tn} \because x$ and $y$ are one in matter. ${ }^{18}$

(A) could be taken as the claim that the matter of $x$ and $y$ are numerically identical, for example, the warm and cold dolphin are numerically identical because their matter is numerically identical. It could also be taken as the weaker claim that they are identical because their matter, while not numerically identical, is spatiotemporally continuous. ${ }^{19}$ I will treat both readings on a par as I want to challenge the claim that Aristotle is committed to any answer to the Conditions Question.

Aristotle never explicitly states (A), but two passages from Metaphysics have been taken to commit him to it. Our first passage is from Met. 5.6, a chapter concerned with the different ways that things are called one. Aristotle distinguishes things called coincidentally one, like the just and the musical (1015b19-20), from things called one in virtue of themselves. Among the latter, he includes examples of things that compose a unity, such as glued wood (1016a1), things that share the same kind of ultimate substratum, such as oil and wine (1016a21-23), and things that share a genus, such as the species horse, human, and dog (1016a27-28). Towards the end of the chapter, he introduces a different way that things are called one:

Again, some things are one in number, others in species, others in genus, others by analogy; in number those whose matter is one, in species those whose formula is one, in genus those to which the same figure of predication applies, by analogy those which are related as a third thing is to a fourth. (1016b31-35)

In this passage, Aristotle distinguishes one in number from one in species, one in genus, and one in analogy. By 'one in number', he means 'numerical identity' ${ }^{20}$ Aristotle also claims that those things that are numerically identical are one in

18. (A) treats 'substance' as the relevant sortal that embodies a criterion of identity. This criterion applies to all substances equally and is different from the criterion of identity for, say, changes. Treating 'substance' as a sortal is in tension with the claim that it is the predicates naming the substantial kinds that are sortals (see Footnote 8). Such a criterion would be written with the relevant predicate replacing 'substance' in the antecedent of (A), which would make explicit that $x$ and $y$ belong to the same kind. However, if the sortals embodying criteria of identity for substances are the predicates naming the substantial kinds, there would be a different criterion of identity for each kind of substance, e.g., the criterion of identity for giraffes would be different from the one for tigers. Since interpreters have argued that the relevant criterion of identity is sameness of matter or sameness of form, they are treating 'substance' as the relevant sortal and not the predicates naming the substantial kinds.

19. For example, Alan Code writes that "spatiotemporal continuity of matter can be used ... to explain the conditions under which an object $x$ existing at one time is numerically the same as some object $y$ existing at another" (1978 647-648).

20. Charlton (1972. 243) argues that 'one in number' means 'unity' and not 'numerical identity'. If correct, Aristotle says either (i) $x$ and $y$ compose some one thing if the matter of $x$ is 
matter, for example, Flipper and the friendly dolphin are one in matter, but Flipper and his mate, Lorelei, are not.

Two notes about this claim: first, it has unrestricted scope; it applies to horses, dogs, colors, and time. It is unlikely that Aristotle intends it to have such scope. If he did so intend it, he would be committed to the claim that if matter $x$ and matter $y$ are one in matter, then matter $x$ is identical to matter $y$. But Aristotle does not seem interested in describing or explaining the identity of matter. His primary interest is the identity of en-mattered things vis-a-vis the matter that they posses. Second, the claim does not mention time; it does not state that those things existing at different times are one in number which are one in matter. But Aristotle's other claims about oneness in this passage apply both synchronically and diachronically, for example, his claim that two things are one in species if their formula is one applies to two things existing at different times. So, I will concede that our passage speaks to both synchronic and diachronic numerical identity. Thus, I concede that Aristotle claims that numerically identical substances existing at the same or different times are one in matter.

Does it thereby follow that Aristotle is committed to (A)? If it does, then he seems committed to an inadequate answer to the Conditions Question, a question he never asks. Assume that 'one in matter' means 'numerically identical matter'. Furth has argued that having numerically identical matter is neither necessary nor sufficient for an identity to hold between substances existing at different times 1978 , 641-642). ${ }^{21}$ It's not necessary because there are differences in the quantities of the four elements that compose, say, the warm dolphin now and the cold dolphin from earlier. Since the dolphins are numerically identical, possessing numerically identical matter is not necessary for an identity to hold through time. It's not sufficient because nothing prevents the very quantity of elements that compose Flipper today composing a numerically distinct substance in the future. ${ }^{22}$

One might respond that Aristotle is just committed to an inadequate view; the fact that a proposed criterion of identity is inadequate does not, by itself, entail that Aristotle is not committed to it. But we should only attribute to Aristotle a poor answer to a question he never asks if his explicit statements clearly entail that answer. And our target passage does not obviously entail (A). A weaker reading of the passage leaves Aristotle only identifying an extensional equivalence between those things that are one in number and those that are one in matter:

continuous with the matter of $y$, or (ii) $x$ is a unity if the matter of $x$ is continuous. On either (i) or (ii), this passage does not concern numerical identity at all, which would be congenial to my overall argument. But Cohen (1984 44-47) convincingly argues that 'one in number' is a two-place relation and should be taken as 'numerical identity' and not 'unity', though I do not accept Cohen's claim that Aristotle is committed to Criterialism. See also Kirwan (1971. 139-140).

21. See also Fine (1994).

22. See Ainsworth (2016) for a survey of the responses to this objection. 
(B) For any $x$, for any $y$, if $\mathrm{x}$ is a substance and $\mathrm{y}$ is a substance, $x$ at $\mathrm{t} 1=y$ at $\mathrm{tn}$ iff $x$ and $y$ are one in matter.

According to (B), if Flipper and the friendly dolphin are one in matter, then Flipper and that friendly dolphin are numerically identical, and vice versa. But (B) does not state a criterion of identity. (B) is compatible with not only (A) but also with the claim that $x$ and $y$ are one in matter because $x$ and $y$ are identical. ${ }^{23}$ Thus, the mere extensional claim that those substances that are one in number are those that are one in matter does not entail that such identities are explained in terms of oneness of matter (or in terms of anything else).

One might object that the context of this passage supports the explanatory reading (A) and not the mere extensional reading (B). ${ }^{24}$ Throughout Met. 5.6, Aristotle explains why things are one in some of the ways that he identifies. For instance, he writes that horse, man, and dog are one in genus because they are all animals (1016a27). One might argue that the entire chapter serves to explain why things are one in the various ways identified. If that were the case, the more plausible reading of our passage would be (A) and not (B). However, this reading of the chapter cannot be sustained; Aristotle does not explain why things are one in each of the ways he identifies. Consider the following claim:

In general those things the thought of whose essence is indivisible, and cannot separate them either in time or in place or in definition, are most of all one, and of these especially those which are substances. (1016b1-3)

Aristotle observes that things are one whose thought of their essence is indivisible. He certainly believes that $x$ and $y$ are one iff the thought of their essence is indivisible. But if this passage is read as explaining oneness, then Aristotle is committed to the claim that things are one because the thought of their essence is indivisible, which would commit him to the view that facts about our thought explain why things are one. A similar issue arises with our target passage. Aristotle claims that those things are one in species whose formula are one. Is he thereby committed to the claim that Flipper and Lorelai are one in species because they have the same formula? If he is, then he is committed to the view that facts about how we speak explain why things belong to the same species. I do not think that we should attribute such a controversial claim to Aristotle on such little evidence, especially since the weaker extensional claim, $x$ and $y$ are one in species iff they are one in formula, is available. Similarly, we should not attribute (A) to

23. This is a particularly attractive way of explaining how one in matter could be necessary and sufficient for an identity to hold between substances. If the fact that the dolphins are identical explains why their matter is one, then it follows that the dolphins are identical iff they are one in matter.

24. I would like to thank an anonymous referee for pressing me on this point. 
Aristotle, a controversial metaphysical claim about persistence, when the weaker extensional claim (B) is available.

Our second passage is from Met. 7.8, the second in a three chapter discussion of generation. ${ }^{25}$ In this chapter, Aristotle is concerned with whether matter, form, and the compound of both are all generated. He argues that it is compound alone that is generated (1033a24-b19), and he argues that forms' lack of generation does not require that forms exist 'apart' from individual substances in the way posited by Plato (1033b19ff). In the case of natural generations, an actual pre-existing substance is sufficient for generating some form in some matter. In this context, Aristotle makes the following claim:

And when we have the whole, such and such a form in this flesh and in these bones, this is Callias or Socrates; and they are different in virtue of their matter (for that is different), but the same in form; for their form is indivisible. (1034a5-8)

Aristotle has argued that substances are generated when forms are produced in some matter, for example, both Socrates and Callias are generated when a human form is produced in some matter. In the second part of the sentence, Aristotle seems concerned to explain the difference between co-specific individuals: since Callias and Socrates are both wholes consisting of a human form in some flesh and bones, why are they different? It cannot be due to their form, which is the same for both. ${ }^{26}$ So, Aristotle concludes that their difference is due to a difference in their matter, that is, Socrates and Callias are different because their flesh and bones are different.

I make two concessions to my interlocutor. First, I assume that Aristotle is interested in the numerical difference between Socrates and Callias. ${ }^{27}$ Second, I assume that Aristotle is concerned with diachronic numerical difference even though the passage explicitly mentions only a case of synchronic numerical difference. Both concessions leave a reasonable reading of our second passage and leave an attractive reading of hylomorphism: the form of a substance explains why it is the kind of substance that it is. There is one form for each kind, and

25. For the relation between these three chapters and Met. 7 as a whole, see, for instance, Bostock (1994 119-120), Burnyeat 2001 29-38), and Ross (1924 Vol. II, 181).

26. Some translate 'eidos' as 'species' and take Aristotle to claim that Socrates and Callias belong to the same infima species. Others translate 'eidos' as 'form' and take Aristotle to claim that Socrates's and Callias's forms are numerically identical. The first reading leaves open whether Callias and Socrates possess numerically distinct forms while the second seems to preclude it. For discussion, see Frede and Patzig (1988 Vol. I, 48-57), Irwin (1988 252), and Ross 1924 Vol. II, 187).

27. This assumption is challenged by Charlton (1972. 244). He argues that Aristotle's concern is the epistemological question of how we are able to distinguish Callias and Socrates. See Cohen 1984 49-50) for a convincing response. 
this one form is said of the many members of the same kind existing at the same and different times. In contrast, the matter of each substance is unique to it. The differences between co-specific individuals, including their numerical distinctness, is explained by a difference in their respective matter.

While this is a reasonable reading of our passage, it does not entail that Aristotle explains numerical identity in terms of oneness of matter. The reason is that explanations of numerical distinctness do not entail explanations of numerical identity. This point is made obvious by considering how Aristotle offers many explanations of numerical distinctness. For instance, in Top. 7.1 he discusses twelve different topoi, or tests, for numerical identity and distinctness. Each of these are reasonable explanations of numerical distinctness. Discussing two will suffice:

(C) If $x$ is a substance and $y$ is a substance, if $x$ and $y$ are not co-generated and co-destroyed, then $x$ is not identical to $y$.

(D) If $x$ is a substance and $y$ is a substance, if $x$ and $y$ are not co-located, then $x$ is not identical to $y$.

Aristotle thinks that a substance is generated when a male informs some menses with the relevant form. Thus, each substance is generated through some distinct generative act. So, if Callias and Socrates are generated via distinct generative acts, they are numerically distinct. Likewise, Aristotle thinks that it is impossible for two bodies to fully occupy the same location. Thus, if Socrates and Callias occupy distinct locations, they are numerically distinct.

(C) and (D) provide sufficient evidence of numerical distinctness. Socrates and Callias occupying different locations entails they are distinct, so too does the fact that different generative and destructive acts created them and will destroy them. But (C) and (D) do not entail any explanation of why identities hold when they do so. For instance, (D) does not entail that Flipper and the friendly dolphin are identical because they are co-located. It does not entail it because (D) is compatible with the claim that Flipper and the friendly dolphin are co-located because they are numerically identical. Thus, the fact that Aristotle accepts (D), or any other explanation of numerical distinctness, does not entail that he accepts any specific criterion of identity.

\section{Form}

On an alternative interpretation, Aristotle believes that identity through time for substances consists in sameness of form:

(E) For any $x$, for any $y$, if $x$ is a substance and $y$ is a substance, then $x$ at $\mathrm{t} 1=y$ at $\operatorname{tn} \because$ the form of $x$ is identical to the form of $y$. 
Furth writes that, for Aristotle, "the 'principle of diachronic individuation' in the sense of the source of the transtemporal unity of a single individual, is form" 1978. 644). Calling the form of an object its organization, Frede argues, "In the case of living things, it is also clear that this continuity of organization or capacity for functioning constitutes the identity of the thing over time" (1987; 67).

Aristotle nowhere claims that substances existing at the same or different times are identical because they are one in form. But interpreters like Furth and Frede argue that (E) is either presupposed or entailed by his explicit commitments. ${ }^{28}$ Perhaps the best argument of this type is that (E) is entailed by the conjunction of Aristotle's answers to the following two questions:

Why does a substance belong to the kind that it does?

Why is an individual substance one unified thing and not a plurality of things?

Our first question asks why a substance is a member of one kind rather than another. Why is Flipper a dolphin and not a giraffe? Aristotle's answer has two parts. First, he believes that kinds of living organisms are individuated by characteristic activities and changes. ${ }^{29}$ Baby dolphins grow into adult dolphins but not adult giraffes. They swim but do not walk. They echolocate but do not smell. For convenience, I will coin the phrase change profile to describe the capacities for those characteristic changes and behaviors essential to each kind. Second, the form of a substance explains why a substance has the change profile of some kind rather than another. For instance, Flipper's form explains why Flipper can swim, echolocate, etc. (Set aside the question whether form is identical to the capacities or whether it explains the possession of these capacities.) Thus, form explains why a substance is the kind of substance it is, for example, Flipper's form explains why Flipper is a dolphin (since it explains why Flipper has the change profile of a dolphin).

Our second question asks why an individual substance is one unified thing and not a plurality of things. Why is Flipper one individual thing and not a mere collection of things like a school of dolphins or a heap of sand? In order to answer

28. Whiting (1986) argues that Aristotle must accept (E) because sameness of matter cannot be what identity through time for substances consist in. This argument assumes that Aristotle believes that identity through time consists in something at all, which is the question at hand, so I will not discuss her argument here.

29. Aristotle's classification and individuation of kinds is complicated. On the one hand, he thinks that it is the activities characteristic of a kind that are fundamental to it, including the activity of creating new members of the same kind (415a26-29, 425a10). By reproducing, Aristotle thinks that organisms can partake of the eternal and divine (415a29-b1). Some think that partaking of the divine is the end of each substance. For discussion, see Cooper (2004a), Johnson (2005), and Rosen (2014). 
this question, Aristotle must explain why the matter of a substance composes one thing as opposed to a plurality of things. His answer appeals to the form of the substance (see Met. 7.17, 1041b7ff; 8.6, 1045a7-12). As an analogy, consider how the parts of a shoe are not a mere heap. They compose some one object, a single shoe. According to Aristotle, it is the form of the shoe that explains why the parts of the shoe compose a unified shoe (Met. 5.6, 1016b12-17). And, more generally, Aristotle believes that form is that in virtue of which the matter of an individual substance composes one unified thing and not a plurality of things.

Allow 'individual' to mean 'one unified thing and not a plurality of things'. Explaining why Flipper is a dolphin seems a different task from explaining why Flipper is an individual. But this does not seem to be the case for Aristotle. Consider how the form transmitted through the father's semen shapes the menses into an animal of the same kind as its parents. ${ }^{30}$ It does so by shaping the menses into organs required for kind-specific capacities. The result is both an individual and a member of some kind. This is why interpreters like Furth believe that, for Aristotle, what it is to be an individual just is to be an individual of some kind. He writes that "the degree to which a kind of thing is 'formed' and the degree to which that kind of thing is "unified' ... merge together" (1978; 638). If this is Aristotle's view, then to explain why a substance is an individual requires explaining why it is an individual F, where F is some kind of thing. Thus, Flipper's form explains why Flipper is an individual by explaining why he is an individual dolphin, and vice versa.

If form explains why a substance is an individual member of some kind at one time, then it will explain why that substance is an individual of the same kind at each subsequent time. Allowing ' $F x^{\prime}$ to mean 'an individual $F$ ', we can express this as follows:

(F) For any $x$, for any $F$, if $x$ is a substance and $F$ is a kind, then $F x$ at $\mathrm{t} 1 \ldots$ tn $\because$ form of $x$.

(F) states that the form of $x$ explains why $x$ is an individual $\mathrm{F}$ at a time and over time. Since Aristotle accepts (F), some interpreters conclude that he also accepts (E), that is, that he accepts that the form of $x$ also explains why $x$ remains the same individual F over time. For instance, Furth claims that Aristotle's answers to both questions show the following:

...it is specific form that is responsible for the continued identity of (e.g.) the individual $F$ through change over time, in that its persistence as numerically one and the same is its persistence as the same $F .(1978,642)^{31}$

30. Following Furth (1978 636).

31. And he claims that "an individual $F$ 's continuing to exist is its persistence as the same $F^{\prime \prime}$ (Furth 1978 641, Footnote 20). 
However, as Code has argued, (F) does not entail (E): an explanation for why $x$ is an individual $\mathrm{F}$ at a time and over time does not entail an explanation for why $x$ remains the same individual $\mathrm{F}$ over time. Code argues that Furth confuses the explanation for why something is an individual and remains one with the explanation of why $x$ and $y$ are either numerically identical or numerically distinct individuals (1978, 648).

To illustrate Code's objection, consider a tray of gingerbread men cookies. Why do the ingredients compose an individual gingerbread man and not some individual butter pecan? The explanation for each cookie being some individual gingerbread man could be the same: there is a set of properties $S$ such that the possession of the properties in $\mathrm{S}$ makes a cookie some individual gingerbread man (as opposed to a butter pecan or caramel shortbread). Included in $\mathrm{S}$ are the relevant temperature of the oven, length of time cooking, etc. But the fact that the properties in $\mathrm{S}$ explain why each cookie is an individual gingerbread man does not entail that these same properties explain why cookies existing at the same or different times are numerically identical: since each gingerbread man will have the properties in S, possession of such properties is insufficient for an identity to hold between gingerbread men.

Likewise, the fact that Flipper's form explains why he is an individual dolphin at a time and over time need not explain why the warm Flipper is identical to the colder Flipper from earlier. ${ }^{32}$ If, for instance, Flipper shares his form with every other dolphin, then that form will explain why each dolphin is an individual dolphin at a time and over time even though possessing the same form will be insufficient for an identity to hold between dolphins existing at different times. Thus, the fact that Aristotle is committed to (F) does not entail that he is committed to (E); he can consistently hold (F) without holding (E).

Some will respond that my objection turns on the vexed question of whether Aristotle believes that forms are unique to their bearers, on whether the form of Callias and the form of Socrates are numerically distinct from one another. If forms are unique to their bearers, then possessing the same form will be sufficient for an identity to hold between substances existing at different times. So, one might respond that if Aristotle accepts (F) and believes that forms are unique to their bearers, then he is also committed to (E).

However, while there is some textual evidence for attributing belief in particular forms to Aristotle, a belief in particular forms does not by itself show that he accepts (E). ${ }^{33}$ If Aristotle were to accept (E), he must argue that possessing the same form is not only a necessary and sufficient condition for an identity to hold

32. Aristotle distinguishes between being an $F$ and being this $F$, where there is a definition of the former but not the latter (see Met. 7.15). A nice example discussed by Cohen (1984) is Aristotle's distinction between being a universe and being this universe in De Caelo 1.9.

33. For an extensive discussion, see Whiting (1984). 
between substances but also that it is an informative and non-circular condition for such an identity to hold. For instance, if Aristotle accepts (E), then he cannot also accept the following criterion of identity for forms:

(G) For any $x$, for any $y$, if $x$ is a substance and $y$ is a substance, the form of $x$ at $\mathrm{t} 1=$ the form of $y$ at $\mathrm{t} n: x=y$.

(E) states that the identity for substances consists in sameness of form, while (G) states that the identity for forms consists in sameness of substance. Thus, (E) and $(\mathrm{G})$ cannot both be true together. ${ }^{34}$ Those who think that Aristotle accepts (E) recognize that he cannot also accept $(\mathrm{G})$. Frede writes that "we certainly cannot individuate forms on the basis of the objects whose forms they are; for the objects themselves are to be individuated by the forms" (1987, 68). ${ }^{35}$ Frede's worry is twofold. First, he thinks that Aristotle must provide a criterion of identity for forms if he is to use particular forms to explain the identity of substances over time. Second, he points out that (E) would be circular, and so inadequate, if Aristotle were to also accept $(\mathrm{G})$. So, to rescue Aristotle, Frede claims that the identity of forms can be explained in terms of their histories (1987: 69), a defense which is not found in any of Aristotle's texts.

This interpretative strategy should give us pause: Frede attributes to Aristotle what he recognizes as a prima facie inadequate answer to a question that Aristotle does not explicitly ask. But why think that Aristotle is committed to this prima facie inadequate answer? The supposed evidence that Aristotle accepts (E) is just that he accepts $(F)$, and $(F)$ is also compatible with $(G)$. Aristotle could consistently believe that Flipper's form explains why he is an individual dolphin at a time and over time, and, at the same time, believe that the forms of the earlier and later dolphins are identical because the dolphins are identical. Analogously, there is no inconsistency between claiming that souls animate bodies, and, at the same time, claiming that the identity through time for souls consists in the sameness of those bodies they animate. This is not to say that Aristotle accepts $(G)$ over (E). It is to say that $(F)$ is compatible with both $(E)$ and $(G)$ regardless of whether or not forms are themselves unique to their bearers. So, the fact that Aristotle accepts (F) does not entail he accepts (E) as opposed to (G). Thus, we do not yet have sufficient evidence for the claim that, for Aristotle, whatever explains why a substance remains an individual $\mathrm{F}$ over time is what identity through time for that substance consists in.

Concluding: I have argued that the evidence that Aristotle is committed to an answer to the Conditions Question is inconclusive. But I do not conclude that

34. See Gill (1994) for similar worries.

35. While Frede mentions individuation in this quote, his focus is what identity through time for substances consists in (see 1987 . 13). 
Aristotle thinks that it has no answer. Bar Aristotle explicitly asking the question and asserting that it has no answer, I do not know how one could prove that. But the fact that he has such little concern for the Conditions Question should give us pause. Since the most distinctive mark of substance is that it persists through change of contraries, we might expect Aristotle to explain how it can do so. That expectation goes unfulfilled if we assume that Aristotle thinks that explaining persistence requires answering the Conditions Question.

\section{The Survival Question}

While the Conditions Question asks one question about persistence through change of contraries, it is not the only one that can be asked. A second and different question asks why various changes of such contraries do not destroy a substance. This question arises for two reasons. First, a substance will be destroyed by some changes but not others. For instance, a fish will die when the water warms significantly but not die when it only warms slightly. Second, a certain change will destroy one substance but not another. For instance, a kitten drowns when submerged in water but a fish does not. The Survival Question asks why this is so; why does a substance survive one change but not another, and why does one change destroy one substance but not another? These questions differ from the Conditions Question. To introduce this difference, consider the following two questions:

1. What are the non-circular, informative, necessary, and sufficient conditions for a ship, $\mathrm{S}_{1}$, at $\mathrm{t}_{1}$ to be numerically identical to a ship, $\mathrm{S}_{2}$, at $\mathrm{tn}$ ?

2. How could $S_{1}$ and $S_{2}$ satisfy these conditions?

Q1 might be asked by those Athenians who wish to know which, if any, of the many ships currently in the harbor is the very ship that Theseus's set sail on to Crete centuries ago. If there were a criterion of identity for ships, then grasping it would allow them to determine which of the current ships is that historic ship. Q2 might be asked by those Athenians who wish to preserve Theseus's ship for posterity, that is, who want to ensure that there is a ship many years hence that is identical to their hero's ship currently sitting in the harbor. Identifying a diachronic criterion of identity will not answer this second question.

Why? A diachronic criterion of identity states the conditions that must be satisfied for an identity over time to hold. But it does not thereby tell us how those conditions can be satisfied, or, to put it slightly differently, it does not tell us how to overcome the obstacles that might prevent those conditions being satisfied. The Athenians are not asking how $\mathrm{S}_{1}$ must be related to some future ship if it is to be identical to that ship. They are asking how they might protect $S_{1}$ from the 
various threats to its continued existence. For instance, they are asking how they might repair $\mathrm{S}_{1}$ without destroying it outright. How can they remove and replace part of the rotting hull without causing a complete collapse of its structure?

It is useful to think of $\mathrm{Q}_{1}$ as a question about persisting through time. It asks of ships existing at two different times the conditions that must be satisfied for them to be identical. The question can be asked even if the ship undergoes no change at all. ${ }^{36} \mathrm{Q}_{2}$ is a question about persisting through change, which cannot be asked in the absence of change. It is a question about how a ship can overcome all the obstacles it faces in getting from, if you will, one time to another.

Q2 does mention criteria of identity. It asks how to satisfy those conditions asked for in Q1. However, questions about surviving change need not be asked in this way. When we ask how to repair a ship without destroying it, we make no explicit mention of criteria of identity at all. When a patriot asks how she might save her nation from an invading enemy, she makes no mention of the conditions under which a nation before and after a successful defense would be identical.

The Survival Question is regularly raised in the study of disease without mention of criteria of identity at all. A standard immunology textbook begins as follows:

Immunology is the study of the physiological mechanisms that humans and other animals use to defend their bodies from invasion by all sorts of other organisms....Infectious diseases are caused by microorganisms, which have the advantage of reproducing and evolving much more rapidly than their human hosts. During the course of an infection, the microorganism can pit a vast population of its species against an individual Homo sapiens. In response, the human body invests heavily in cells dedicated to defense, which collectively form the immune system. (Parham 2015: 1)

The medical student learns about the various cells and tissues of the immune system, innate immunity - "which includes physical and chemical barriers to infection, and responses that are ready and waiting to halt infections before they can barely start" (Parham 2015 2)-as well as the mechanisms of the adaptive immune system that respond when innate immunity has failed. In learning about immunology, students are learning about survival. They are learning how and why some humans are able to survive an illness while others cannot. At no point do they ask about diachronic criteria of identity. Theirs is not the search for the conditions under which the sick patient yesterday and the healthy patient today are identical. Theirs is the attempt to explain how, and hopefully bring it about that, the sick patient survives his illness.

One might respond that our students have some implicit grasp of a diachronic

36. See Shoemaker 1969) for discussion about whether an object could persist through time without changing. 
criterion of identity; even if they do not mention criteria of identity when asking how a patient survives, one might object that a student would be unable to inquire into a patient's recovery if she were unable to somehow grasp what makes the sick patient from yesterday identical to the healthy patient today. This is an issue that I will return to in Section 8 . Here I respond by noting that even if an answer to question $x$ were to entail an answer to question $y$, it would not follow that $x$ and $y$ are identical questions. 'This is where Flipper was last seen' is an answer to both the question 'why is the dolphin photographer here?' and the question 'why are the tourists here?' These are two different questions even though they have the same answer. Similarly, irrespective of whether an answer to the Survival Question entails an answer to the Conditions Question, the two questions, what they explicitly ask, are different.

\section{Case Study: Growth}

Unlike the Conditions Question, Aristotle explicitly asks and tries to answer the Survival Question. One good example of where he does so is On Youth, Old Age, Life and Death, and Respiration, a text that is partly dedicated to the Survival Question. ${ }^{37}$ By the end of the fourth chapter, Aristotle has argued for the following claim:

Hence, of necessity, life must be simultaneous with the maintenance of [natural] heat, and what we call death is its destruction. (469b18-20; see also 470a19-20)

In this passage, Aristotle claims that there is a correlation between an animal's natural heat and its life. ${ }^{38}$ Generation is associated with such heat coming to be (479b29-30). Death occurs when that heat, more precisely the heat in the heart, is destroyed. Anything that destroys this heat will thereby kill the animal:

It is always to some lack of heat that death is due, and in perfect creatures the cause is its failure in the organ containing the source of the creature's essential nature. $\left(478 b_{31-33)}\right.$

In the first part of this sentence, Aristotle states that death is always caused by lack of heat. Since this heat cannot be preserved and the animal continue to exist, the lack of such heat is necessary for death. And since this heat cannot be destroyed and the animal continue to exist, such a lack is sufficient for death. Thus, lack of heat is both necessary and sufficient for death.

37. I focus on sanguineous animals with lungs and gills.

38. His argument for this claim, which relies on his view about the heart and its role in nutrition, is unimportant for my purposes. 
We might ask how to reconcile Aristotle's claim that lack of heat is both necessary and sufficient for an animal to die with his claim that an animal must remain an animal of the same kind. Flipper ceasing to be a dolphin is sufficient for his demise, but maintaining natural heat seems compatible with him ceasing to be an individual dolphin and becoming, say, an individual shark. Why is Flipper unable to retain his core temperature as he migrates species? Of course, Flipper cannot do this, but the question serves to ask how Aristotle understands the relationship between various requirements for Flipper's survival, in this case the requirement that he retain a stable core temperature and the requirement that he remain an individual dolphin.

The answer is that Aristotle associates different quantities of natural heat with different kind-specific capacities. For instance, he believes that humans are the hottest animals. This heat explains why we have an upright posture, "for heat promotes growth...and thus it is that man is the most erect of animals" (PA 3.6, 669 b3-6). We need an upright posture, according to Aristotle, because "it is the function of the god-like to think and to be wise", a function we could not fulfill if we were "under the burden of a heavy body, pressing down from above and obstructing by its weight the motions of the intellect and of the general sense" (PA 4.10, 686a25-32). Since we are intelligent, we must have an upright posture. And to have an upright posture, our bodies must be sufficiently hot. 39 So, an animal dies when it not only goes completely cold but also when it loses that heat required for its kind's change profile, for example, Flipper dies when he loses that heat required for a dolphin's change profile.

Since an animal dies if it loses its natural heat, it must retain that heat as it changes. And Aristotle says that there are puzzles about how animals are able to do this, especially how they are able to retain this heat as they grow. Growth involves food in the stomach being concocted, which for our purposes we can think of as similar to cooking. Food is only transformed into nutriment, something that can be used by the organism to grow and sustain its parts, once it has been cooked. $4^{0}$ This process uses the animal's heat. But, Aristotle observes, such a process generates further heat, just as adding fuel to any fire makes it hotter. This poses a risk to the organism. Like a fire feeding on more fuel, Aristotle worries that the heat will accumulate and exhaust itself, that is, the fire will burn up all of its available fuel (469b27-31). If the natural heat is exhausted, then the animal dies. So, given that growth involves processes that threaten the animal, Aristotle

39. These claims are not restricted to humans. The quantity of heat affects the nature of an animal's blood, and the nature of the blood "affects the temperament and the sensory faculties of animals in many ways" (PA 2.4, 651a12-17). By this, Aristotle means that variations in temperature, thickness, and transparency correspond with various capacities. For some recent discussion, see Ebrey (2015) and Gelber 2015). (1982).

40. For a book-length discussion of concoction, see Freudenthal (1995). See also Boylan 
asks how animals survive growing at all. And he observes the following:

Clearly, therefore, if the bodily heat must be conserved (as is necessary if life is to continue), there must be some way of cooling the heat resident in the source of warmth. (470a5-7)

Three observations: first, this is a problem about persistence, in particular, it is an instance of the Survival Question: how are animals able to survive the life threatening processes involved in growth? Growing safely requires an animal's internal temperature to remain stable as it grows, but digestion generates further, potentially fatal, heat. So, in order to grow safely, animals require this heat to be refrigerated. If Aristotle can explain this refrigeration, he will have explained how organisms survive growth.

Second, this problem is an instance of a more general one. Aristotle identifies various ways for an animal to die, both naturally and violently (479a32-479b3). Violent death includes disease, suffocation, etc. Natural death includes old age, which "is the exhaustion [of the natural heat] due to inability on the part of the organ, owing to old age, to produce refrigeration" (479b4-5). As we age, the lungs harden and become less effective in refrigerating the natural heat, ultimately resulting in our heat being exhausted. The Survival Question arises whenever some change causes a violent or natural death to one animal but not another, and whenever some animal survives some change but not another.

Third, since an animal dies when the natural heat "is no longer tempered by cooling" (479a7-9), explaining survival through growth requires explaining how the heat can be so tempered. Aristotle does this by appeal to respiration and its organs, lungs or gills. Respiration dampens the heat but not so much as to undermine the body's capacity to further digest food. Aristotle says that it is like a coal fire. If the choker covers up the coals in a brazier, the fire is exhausted. But if the lid is lifted up and put down again in succession, the coal remains glowing for a long time at a stable temperature (470a5-15). Similarly, by inhaling and exhaling, excess heat is removed, which allows the animal to digest and grow safely. Aristotle subsequently engages in a lengthy investigation of respiration, ultimately identifying its formal, final, efficient, and material causes. For instance, he diagnoses the failures of his predecessors to account for respiration as follows:

The main reason why these writers have not given a good account of these facts is that they have no acquaintance with the internal parts, and that they did not grasp that nature does everything for the sake of some end. If they had asked for what purpose respiration exists in animals, and had considered this with reference to the parts, e.g. the gills and the lungs, they would have discovered the reason more speedily. (471a23-29) 
Aristotle here criticizes his predecessors for failing to identify the final cause of respiration and the parts of the respiratory system, whether they be gills in fish or lungs in mammals, birds, etc. He will argue that the final cause of respiration is refrigeration, which in turn serves in humans to ensure a stable temperature sufficient for our upright posture (475 $\mathrm{b}_{5} \mathrm{ff}$ ). The efficient cause is the heart, in particular the way in which it causes an expansion and retraction of the lungs, and the material cause relates to the spongy character of the lungs and its various airways (480a16ff).

Aristotle's criticism and response to his peers obviously relies on his view from Phys. 2 that there are four causes. For instance, it relies on the claim that there are final causes and that bodies stand in some relationship to these final causes. Fully characterizing how Aristotle deploys his four causal schemata to explain survival through growth is beyond the scope of this paper. But, whatever the correct characterization of the answer, the question that it is an answer to is the Survival Question.

\section{Aristotle's Answer to the Survival Question}

While I will not fully characterize how Aristotle explains survival through growth, I want to sketch how I understand his general answer to the Survival Question; a sketch as I provide only sufficient details to contrast the Survival from the Conditions Question.

In order to answer the Survival Question, Aristotle must explain how a substance retains its kind-specific capacities as it changes, since, for Aristotle, kinds are individuated by what they can do. His explanation for how substances retain kind-specific capacities as they change will depend on the kind of substance and the kind of change. But the general form of these explanations will be the same and begins with his account of nature as an internal principle of change and stability in Phys. 2.1:

For each of them [those things that exist according to nature] has within itself a principle of motion and of stability in respect of place, or of growth and decrease, or by way of alteration. (192b13-15; slightly modified. See also 192b20-24)

In this quotation, Aristotle is concerned with the question 'what is nature?' According to one attractive reading of his answer, he claims that a natural being has the change profile it has because of the kind it belongs to. ${ }^{41}$ For example, when an organism grows in shape and size, it does not do so randomly as, say, a fire grows and spreads. Organisms grow in specific structured ways, at specific

41. See Waterlow 1982 Chapter 2) for this reading. See Kelsey 2003 for alternatives. 
rates, and in a limited way (DA 416a15-17). Flipper grew a dorsal fin and not wolf claws. As he grew into an adult dolphin, his flipper and dorsal fin grew in proportion to one another. It is his nature, according to Aristotle, which explains why he and his parts grew in the way that they did.

Aristotle also claims that nature is an internal principle of stability in respect of motion, alteration, and growth. It is this claim that will provide his general answer to the Survival Question. Why? When a substance changes, it changes in some respects and not others. As Flipper warms up, he retains his shape. As he swims, he retains his size. By claiming that nature is an internal source of stability, Aristotle wants to emphasize that the nature of a substance explains why it remains unchanged as much as it explains why it does change. How does it explain it? In Met. 9.1, Aristotle distinguishes the potentiality to be changed from the potentiality to remain unchanged:

For one kind is a potentiality for being acted on, i.e. the principle in the very thing acted on, which makes it capable of being changed and acted on by another thing or by itself regarded as other; and another kind is a state of insusceptibility to change for the worse and to destruction by another thing or by the thing itself qua other, i.e. by a principle of change. (1046a11-15)

By calling nature an inner principle of stability, I take Aristotle to mean that the nature of the substance explains why it has the various potentials to remain unchanged that it does. This is not all that Aristotle means by this claim, but it is the claim that is relevant here. It is also a reasonable claim to make. The nature of a substance could not be an internal source of change if it were not also an internal source of stability. A person could not successfully get a tattoo, experience a change in skin hue, if she fell to the floor at the touch of tattoo artist's pen. Being successfully tattooed requires the capacity to resist being moved in place while one is being changed in color.

Since the nature of a substance explains why it remains unchanged in some ways as it changes in others, nature provides an answer to the Survival Question. As an analogy, compare a saw made of ice to an iron saw. Both have sharp and jagged teeth, but only one can be used for sawing timber. If you were to use the ice saw for that task, you may make an initial imprint but the kinetic energy produced by the friction will generate heat that destroys it. In contrast, iron is a resilient material. The heat produced by an iron saw neither melts the iron nor blunts the teeth in any deleterious way. The iron saw has a source of stability in respect of shape that the ice saw does not. And it is this source of stability that explains why the iron saw can retain its shape and survive as it is being used to cut. Similarly, since the nature of a substance explains why it remains stable in one way as it changes in another, its nature explains how it survives 
being changed. For instance, Flipper survives growth only if he remains stable in respect of temperature. This stability is explained by the lungs and other parts of the respiratory system. Since Flipper's respiratory system is explained by his nature, his nature explains how he survives growth.

This is only a sketch of Aristotle's general answer to the Survival Question. In order to add detail, we would need to characterize how the nature of a substance explains why that substance has various potentials to remain unchanged. Such a project is beyond the scope of this paper as it depends on more general questions about how Aristotle uses form and matter to explain any natural phenomena. Importantly, it requires deciding whether matter makes an independent contribution to those explanations. By 'independent', I mean to ask whether an animal's matter explains any part of an animal's change profile without itself being explained by anything further. It is beyond the scope of this paper to settle this issue, but I will describe why it would be relevant if we were to fully characterize Aristotle's answer to the Survival Question.

In Phys. 2.9, Aristotle argues that a substance has the matter that it has because of the form that it has. One premise in his argument for this claim is that the body and its parts come into being for the sake of the end (200a32-20ob4). Just as a saw is made for sawing, the body of an animal is such that it can do what members of its kind can do. For instance, since dolphins move by swimming, they must possess a body that allows them to swim. Since they eat fish, they must possess teeth suitable for fish eating. Aristotle thereby thinks that a body comes into being and grows as it does in order for the organism to be able to carry out the activities specific to its kind..$^{2}$ He concludes that a substance has the parts that it has because of its form, for example, an animal has lungs and respires because of its form.

However, Aristotle elsewhere seems to deny that every part of the body comes into being for the sake of the organism, and so he seems to deny that form explains why a body has every part that it has. For instance, Aristotle thinks that there are residues at each stage of the nutritive process. These residues seem to come to be by material necessity and not for the sake of the animal. Nevertheless, Aristotle thinks that some of these residues do constitute parts of the animal's body. After food undergoes its first stage of concoction in the stomach, a by-product is formed that is used to replenish and grow things like fat, hair, and nails (GA 2.6, 744b11). But fat, hair, and nails do not seem to have come to be for the sake of the animal. Rather, "heat and cold and the motions they set up as the bodies are solidified by the hot and the cold are sufficient to form all such parts as are the homogeneous bodies, flesh, bone, hair, sinew, and the rest" (Meteor. 4.12, 39ob2-6). Various mixtures of the hot and cold give rise to various degrees of ductility, malleability,

42. This is what Aristotle means by calling form the final cause of a substance (198a24-26). The details are controversial. See Rosen (2014) for discussion. 
hardness, etc., and various sets of these features distinguish these homogenous bodies, for example, bones are less malleable than sinews (39ob6-9). So, at least some facts about the substance's body do not seem explained by its form. Rather, they seem explained by its matter independently of its form.

If Aristotle thinks that an animal's form explains why it has the body it has and behaves the way it does, then form alone will provide our answer to the Survival Question; Flipper will survive growing because of his form. If Aristotle thinks that matter makes an independent contribution to the explanation of an animal's change profile, then both form and matter together will provide our answer to the Survival Question. It is beyond the scope of this paper to settle such a vexed issue; this paper is concerned with identifying the question Aristotle asks and not the answer that he defends. ${ }^{43}$ So, I will continue by saying that an animal's nature explains its change profile and remain neutral as to whether this nature is form alone or form in addition to matter.

Let me sum up with three points. First, a substance can survive change only if it can remain stable in those ways required to support its kind-specific activities, for example, Flipper's temperature cannot increase too drastically as he eats. Second, the body of a substance is so organized to maintain stability in these various respects, for example, Flipper has the appropriate respiratory system for maintaining his core temperature as he eats. Third, the nature of a substance explains why it has the body it has. These three claims provide an answer to the Survival Question: a substance is not destroyed as it changes because of its nature.

\section{A Criterialist Response}

The Criterialist and I agree that Aristotle explains persistence. They understand this explanation as answering the question, 'what are the conditions under which the substance before and after the change are identical?'- the Conditions Question. I understand the explanation as answering the question, 'why is the substance not destroyed as it changes?' - the Survival Question. One might object that if Aristotle is committed to an answer to the Survival Question, then he is also committed to an answer to the Conditions Question. There are two ways that this objection could be pressed.

43. For discussion, see Cooper 2004a: 2004b), Ebrey (2015), Gelber (2015), Henry (2013), Leunissen (2010), and Meyer (1992).

Ergo $\cdot$ vol. 5, no. $20 \cdot 2018$ 
Objection 1: an answer to the Survival Question presupposes an answer to the Conditions Question.

The marine biologist who studies why Flipper is not destroyed as he changes is able to keep track and re-identify Flipper over time. One might claim that this ability requires her to posses a criterion that enables her to judge that dolphins existing at two different times are identical. If the practice of answering the Survival Question presupposes Criterialism, one might object that my argument that Aristotle is committed to an answer to the Survival Question presupposes that he is committed to there being some answer to the Conditions Question.

This objection confuses two issues. There is the epistemological question of how we as agents keep track of beings as they change. There is also the metaphysical question of what the identity through time of these beings consists in. The answers to these two questions may come apart. Some think that personal identity consists in sameness of soul, which we cannot perceive, and also think that we keep track of persons over time by attending to sameness of body, which we can perceive. Still others think that our ability to single out and keep track of objects is independent and prior to our ability to investigate what their identity consists in. On such a view, we first know that this tiger and that tiger are identical before we inquire into what makes them identical. ${ }^{44}$ Of course, some do see a close connection between the metaphysics and epistemology of identity over time. David Wiggins (2001) thinks that the semantic life of the concept of identity is determined by our practices of individuating. One way of reading this claim is that, for Wiggins, facts about what identity consists in are determined by facts about how we as agents identify and keep track of beings over time. ${ }^{45}$

I do not offer a positive interpretation of Aristotle's epistemology of persistence. All I need to observe is that Aristotle's belief that a biologist keeps track of Flipper over time as she investigates his survival does not entail that he accepts one of these views about how the biologist is able to do so, including the view that the biologist does so by grasping and applying the criterion of identity for dolphins (if there is one). Thus, without further evidence, we should not assume that Aristotle believes that the practice of answering the Survival Question presupposes Criterialism.

Objection 2: the answer to the Survival Question entails an answer to Conditions Question.

If a biologist discovers that Flipper's nature explains why he is not destroyed as he swims, one might claim that possessing the same nature explains why the dolphins

44. See, for instance, Campbell (2002).

45. See Lowe (1989), Perry (1975), and Parfit (1971) for discussions about the relationship between the metaphysics and epistemology of criteria of identity. 
before and after a particular swim are identical. That is, one might object that Aristotle's answer to the Survival Question commits him to a particular answer to the Conditions Question, namely, that identity through time for substances consists in sameness of nature. In response, I want to show that Aristotle's answer to the Survival Question is compatible with both the truth and falsity of Criterialism. If his answer is compatible with the falsity of Criterialism, then it does not entail Criterialism.

To deny Criterialism is not to deny that identities at a time and over time hold. Rather, it is to deny that the holding of such identities is explained by the satisfaction of any criterion of identity. This view, Anti-criterialism, says that facts about identities holding are brute. How do we understand this claim? Identity is a relation that holds between each thing and itself, and nothing else. It is reflexive, transitive, and symmetrical..$^{6}$ By claiming that identity is brute, the Anti-criterialist means that the relation holds not in virtue of any other facts about the relata holding. This contrasts to a relation like being taller than that holds because of certain other facts about the relata, in particular, facts about the respective heights of the relata. The Criterialist thinks that identities hold because of various facts about the relata, for example, the defendant and prisoner are identical because they are psychologically continuous. This is precisely what the Anti-criterialist denies. She accepts that the identities hold, but she denies that they hold because of the satisfaction of any criterion of identity.

So, the Anti-criterialist does not deny that Flipper persists as he swims. She can even accept that there are necessary and sufficient conditions for an identity holding. Consider, for instance, the property of being the only person in the room. This bi-conditional states a necessary and sufficient condition for personal identity:

For any $x$, for any $y$, if $x$ is a person and $y$ is a person, then $x=y$ iff if $x$ is the only person in the room, then $y$ is the only person in the room, and vice versa.

This states that our defendant and prisoner are identical on the condition that if the defendant has the property of being the only person in the room, then our prisoner has the property of being the only person in the room, and vice versa. While this is a necessary and sufficient condition for personal identity, it is not an adequate criterion of personal identity. It is inadequate because it is uninformative. The property of being the only person in the room just is the property a person, $S$, has if (i) $S$ is in the room, and (ii) for any person, $R$, if $R$ is in the room then $S=R$. Claim (ii) presupposes what we are trying to analyze in the first place, namely, personal identity. Thus, it is not an adequate criterion

46. There is some debate as to whether identity is an intrinsic or extrinsic relation. For discussion, see Noonan 1989) and Wiggins 2001. 
of identity. Denying Criterialism, then, does not force one to deny that there are necessary and sufficient conditions for identities to hold. The Anti-criterialist is denying that these conditions are ever adequate criteria of identity.

Some interpreters have argued that Aristotle is an Anti-criterialist. William Charlton, for instance, writes that for Aristotle "there is no such thing as what it is for an object identified on one occasion to be identical with an object identified on another" (1994 41).47 Charlton does not deny that, for Aristotle, substances remain numerically one and the same as they admit contraries. Rather, he denies that, for Aristotle, there are non-circular, informative, necessary, and sufficient conditions for any identity to hold.

While I do not defend Anti-criterialism as an interpretation of Aristotle, I do claim that Aristotle's answer to the Survival Question is compatible with it. $4^{8}$ Since this answer is compatible with both Criterialism and its denial, it does not entail Criterialism (which is the objection under consideration).

One way of seeing that it is compatible with both Criterialism and its denial is by noticing that Aristotle's answer to the Survival Question is unsuited to adjudicate puzzles of diachronic identity. Consider a version of the fission cases discussed in the personal identity literature. ${ }^{49}$ Suppose a young Lieutenant, William Thomas Riker-Riker for short-undergoes brain surgery. ${ }^{\circ}$ Half of his brain is removed and put into one donor body. Call the resulting person Thomas. The other half of Riker's brain is put into a second donor body. Call him William. Who is the original Riker? Since Thomas and William are numerically distinct from one another, both cannot be identical to Riker. Brain operations normally preserve numerical identity, so, as Derek Parfit claims, we have no reason to think that being doubly successful counts as a failure (1971: 5). Thus, numerical identity should have been preserved, but it seems arbitrary to pick either William or Thomas as the original Riker.

The Criterialist will claim that there is a fact of the matter as to whether it is Thomas or William who is identical to Riker, and she will also claim that this fact is explained by some deeper fact, namely, that one of Thomas or William along with Riker satisfies the criterion of identity for persons. Indeed, a Criterialist will claim that a test of various candidate criteria of identity just is whether they can allow a satisfactory solution to this puzzle and others like it. If, for instance, a candidate criterion entails that Riker is identical to both William and Thomas, then

47. See also Charlton (1972 242) and Bowin 2008 85-87).

48. To claim that Aristotle is not committed to Criterialism is not equivalent to claiming that he is committed to Anti-criterialism. His answer to the Survival Question entails neither of these two positions, or so I argue.

49. See Wiggins (1967 50) and Parfit (1971).

50. This example is a modification of the perplexing situation that arises from a transporter accident on 'Second Chances', Star Trek: The Next Generation, Season 6, Episode 24. The fission case I discuss here arises from a brain operation and not a transporter accident. 
it is inadequate (because it is not sufficient) and must be discarded or amended. The Anti-criterialist, on the other hand, will claim that it is a brute fact that an identity holds, for example, if Riker is identical to Thomas and not William, then this is a brute fact that is explained by nothing further.

Aristotle's answer to the Survival Question entails no answer as to who is or is not Riker, and, as such, it is compatible with both the Criterialist and Anticriterialist responses to the puzzle. On Aristotle's view, the nature of Riker will explain how Riker remains a human being as the surgeon's saw begins to cut into his skull. The friction caused by the saw, which would cause some kindling to catch fire, does not cause the body to catch fire. Similarly, the sharpness of the saw, which would destroy a balloon upon contact, does not cause Riker's body to burst. Why does Riker not catch fire and burst as the saw pierces his skin? Aristotle's answer is that Riker has a body that is able to resist these deleterious effects as he is undergoing a surgery. And he has the body and bodily parts he has because of his nature. Thus, Riker's nature explains why he survives the surgery.

Suppose that Riker turns out to be Thomas and not William. On my interpretation, Riker's nature will explain how Riker retains the various essential capacities of a human as half his brain is being transferred into a new body. The Criterialist will claim that if Riker's nature explains how he remains a person as he becomes Thomas, then sameness of identity for persons consists in sameness of nature. This is a leap. Riker's nature could explain how Riker remains a person as he becomes Thomas without there being a criterion of identity for persons. That is, the Anti-criterialist can accept that Riker's nature explains why he is a person and remains a person without thereby accepting that identity for persons consists in anything at all. As one prominent Anti-criterialist, Trenton Merricks, puts it, "I say that being a member of a certain kind and lasting over time are disparate features of an object" (1998 113). How might the Anti-criterialist sustain such a view? Consider the following bi-conditional:

(H) For any $x$, for any $y$, if $x$ is a substance and $y$ is a substance, then $x$ at $\mathrm{t} 1=y$ at tn iff the nature of $x$ is identical to the nature of $y$.

(H) provides a necessary and sufficient condition for Riker and Thomas to be numerically identical. An Anti-criterialist could accept $(\mathrm{H})$. What they deny is that this bi-conditional entails an explanation for why Riker is numerically identical to Thomas. They deny that any side of this bi-conditional has explanatory priority. But this denial is perfectly compatible with the claim that Riker's nature explains how he remains a human as he becomes Thomas.

I have not argued that Aristotle is an Anti-criterialist; his answer to the Survival Question is compatible with both Criterialism and its denial, so it does not entail either. Nevertheless, the Anti-criterialist may find my interpretation 
particularly congenial. One objection to Anti-criterialism is that it is unable to offer any explanation of persistence. It seems to leave it mysterious how entities persist through change. But this accusation misses the mark. The Anti-criterialist can consistently attempt to explain why entities are not destroyed as they change. They need not remain silent on this question just because they argue that there are no criteria of identity. They may also offer the following retort: even if there are criteria of identity, identifying them does not answer some of the most pressing questions about persistence. A medical student puzzling how an elderly patient survived septic shock will fair poorly with her teachers if she reports, "the patient with sepsis persisted because the healthy patient today and the septic patient from yesterday have identical bodies." This answer to the Conditions Question does not entail an answer to the Survival Question, which is the relevant question in this case. If Aristotle's explanation of persistence is inadequate because it does not answer the Conditions Question, Criterialism without an answer to the Survival Question is also an inadequate explanation of persistence.

\section{Conclusion}

Let me conclude by considering a final objection. One might concede that Aristotle's explicit claims do not commit him to an answer to the Conditions Question in the texts that I have considered. However, one might object that I have not precluded the possibility that Aristotle does, nevertheless, have an answer to the Conditions Question. I have considered the main textual evidence, so I believe that the onus is on my detractor to rebut my readings of those texts or identify alternative texts that I have not considered.

Nevertheless, I suspect that some will respond that Aristotle must be committed to an answer to the Conditions Question given his interest in persistence. They will claim that adequately explaining how Flipper survives warming up requires identifying what his identity through time consists in. Thus, they will conclude that my reading of Aristotle is particularly unattractive because it leaves him with an inadequate explanation of persistence.

This objection assumes a substantive metaphysical position, namely, it assumes that explaining persistence requires answering the Conditions Question. This is a substantive position; there is a rich philosophical debate about whether there are any diachronic criteria of identity at all. Aristotle's position in this debate is underdetermined by the texts, and so we cannot assume that he agrees with those who insist that explaining persistence does require answering the Conditions Question. There is also little evidence of the Conditions Question being asked and debated by Aristotle's peers and predecessors. It is not until the Stoics that puzzles of persistence and criteria of identity play a role in 
metaphysical inquiry..$^{51}$ So, I will leave it to my detractors to identify evidence that Aristotle would agree that explaining persistence requires answering the Conditions Question.

Before we can identify Aristotle's answer to the question, 'how does Flipper remain numerically one and the same as he admits contraries?', we must clarify what we are asking of him. There is little evidence that Aristotle would characterize this question as an instance of the Conditions Question but ample evidence that he would characterize it as an instance of the Survival Question. Thus, I propose that we stop asking Aristotle for criteria of identity and focus instead on the ways that he really does explain persistence.

\section{Acknowledgments}

I would like to thank audiences at Cornell and Marquette for helpful discussion and feedback. For helpful discussion and comments on previous versions, I would like to thank David Bronstein, David Charles, Timothy Clarke, Cristina Ionescu, Harvey Lederman, Marko Malink, Colin McLear, Amy Rupert, Whitney Schwab, Rachel Singpurwalla, and two anonymous referees for Ergo. I especially would like to thank Gail Fine, Terence Irwin, and Theodore Brennan for extensive discussion and comments on an earlier attempt to distinguish the Conditions from the Survival Question in my doctoral dissertation.

\section{References}

Ainsworth, Thomas (2016). Form vs. Matter. In Edward N. Zalta (Ed.), The Stanford Encyclopedia of Philosophy (Spring 2016 ed.). Retrieved from https: / plato.stanford.edu/entries/form-matter /

Anscombe, G.E.M. (1953). The Principle of Individuation. Proceedings of the Aristotelian Society, Suppl. Vol. 27, 83-96.

Barnes, Jonathan (1984). The Complete Works of Aristotle: The Revised Oxford Translation. Princeton University Press.

Bostock, David (1994). Aristotle: Metaphysics Books Z and H. Clarendon Press.

Bostock, David (2006). Aristotle's Theory of Matter. In Space, Time, Matter, and Form: Essays on Aristotle's Physics (30-47). Clarendon Press.

Bowin, John (2008). Aristotle on Identity and Persistence. Apeiron: A Journal for Ancient Philosophy and Science, 41(1), 63-88.

Boylan, Michael (1982). The Digestive and "Circulatory" Systems in Aristotle's Biology. Journal of the History of Biology, 15(1), 89-118.

Burnyeat, Myles F. (2001). A Map of Metaphysics Zeta. Mathesis Publications.

51. See Sedley $(1982)$ for discussion.

Ergo $\cdot$ vol. 5, no. $20 \cdot 2018$ 
Campbell, John (2002). Reference and Consciousness. Clarendon Press.

Charlton, William (1970, 1992). Aristotle's Physics: Books 1 and 2. Clarendon Press.

Charlton, William (1972). Aristotle and the Principle of Individuation. Phronesis, 17(3), 239-249.

Charlton, William (1994). Aristotle on Identity. In Theodore Scaltsas, David Charles, and Mary Louise Gill (Eds.), Unity, Identity, and Explanation in Aristotle's Metaphysics (41-53). Clarendon Press.

Code, Alan (1976a). Aristotle's Response to Quine's Objections to Modal Logic. Journal of Philosophical Logic, 5(2), 159-186.

Code, Alan (1976b). The Persistence of Aristotelian Matter. Philosophical Studies: An International Journal for Philosophy in the Analytic Tradition, 29(6), 357-367.

Code, Alan (1978). What Is It to Be An Individual? Journal of Philosophy, 75(11), 647-648.

Cohen, S. Marc (1984). Aristotle and Individuation. Canadian Journal of Philosophy, Suppl. Vol 10, 41-65.

Cooper, John M. (2004a). Aristotle on Natural Teleology. In Knowledge, Nature, and the Good (107-129). Princeton University Press.

Cooper, John M. (2004b). Hypothethical Necessity. In Knowledge, Nature, and the Good (130-147). Princeton University Press.

Ebrey, David (2015). Blood, Matter, and Necessity. In David Ebrey (Ed.), Theory and Practice in Aristotle's Natural Science (61-76). Cambridge University Press.

Fine, Kit (1994). A Puzzle Concerning Matter and Form. In Theodore Scaltsas, David Charles, and Mary Louise Gill (Eds.), Unity, Identity, and Explanation in Aristotle's Metaphysics (13-40). Clarendon Press.

Frede, Michael (1987). Individuals in Aristotle. In Essays in Ancient Philosophy (49-71). University Of Minnesota Press.

Frede, Michael and Patzig, Günther (1988). Aristoteles, Metaphysik Z. C. H. Beck. Frege, Gottlob (1884). The Foundations of Arithmetic, (2nd ed.). Blackwell.

Freudenthal, Gad (1995). Aristotle's Theory of Material Substance: Heat and Pneuma, Form and Soul. Clarendon Press.

Furth, Montgomery (1978). Transtemporal Stability in Aristotelian Substances. Journal of Philosophy, 75(11), 624-646.

Furth, Montgomery (1988). Substance, Form, and Psyche: An Aristotelean Metaphysics. Cambridge University Press.

Gelber, Jessica (2015). Are Facts about Matter Primitive? In David Ebrey (Ed.), Theory and Practice in Aristotle's Natural Science (46-60). Cambridge University Press.

Gill, Mary Louise (1991). Aristotle on Substance: The Paradox of Unity. Princeton University Press.

Gill, Mary Louise (1994). Individuals and Individuation. In Theodore Scaltsas, David Charles, and Mary Louise Gill (Eds.), Unity, Identity, and Explanation in 
Aristotle's Metaphysics (55-71). Clarendon Press.

Hartman, Edwin (1977). Substance, Body and Soul: Aristotelian Investigations. Princeton University Press.

Henry, Devin (2013). Optimality and Teleology in Aristotle's Natural Science. Oxford Studies in Ancient Philosophy, 45, 225-263.

Hirsch, Eli (1982). The Concept of Identity. Oxford University Press.

Irwin, Terence (1988). Aristotle's First Principles. Clarendon Press.

Johnson, Monte Ransome (2005). Aristotle on Teleology. Clarendon Press.

Jones, Barrington (1974). Aristotle's Introduction of Matter. The Philosophical Review, 83(4), 474-500.

Kelsey, Sean (2003). Aristotle's Definition of Nature. Oxford Studies in Ancient Philosophy, 25, 59-87.

Kirwan, Christopher (1971). Aristotle's Metaphysics: Books Gamma, Delta, and Epsilon. Clarendon Aristotle Series. Clarendon Press.

Leunissen, Mariska (2010). Explanation and Teleology in Aristotle's Science of Nature. Cambridge University Press.

Lloyd, A. C. (1970). Aristotle's Principle of Individuation. Mind, 79(316), 519-529. Locke, John (1979). John Locke: An Essay Concerning Human Understanding. P. H. Nidditch (Ed.). Oxford University Press.

Lowe, E. J. (1989). What is a Criterion of Identity. The Philosophical Quarterly, 39(154), 1-21.

Lowe, E. J. (1991). One-Level versus Two-Level Identity Criteria. Analysis, 51(4), 192-194.

Lowe, E. J. (2009). More Kinds of Being. Wiley-Blackwell.

Matthews, Gareth (1982). Accidental Unities. In Malcolm Schofield and Martha Nussbaum (Eds.), Language and Logos (223-240). Cambridge University Press. Matthews, Gareth (1992). On Knowing How to Take Aristotle's Kooky Objects Seriously. Symposium conducted at the Pacific Division meeting of the APA. Merricks, Trenton (1998). There Are No Criteria of Identity over Time. Noûs, 32(1), 106-24.

Meyer, Susan Sauve (1992). Aristotle, Teleology, and Reduction. The Philosophical Review, 101(4), 791-825.

Noonan, Harold W. (1989). Personal Identity. Routledge.

O'Connor, Scott (2015). The Subjects of Natural Generations in Aristotle's Physics

I.7. Apeiron: A Journal for Ancient Philosophy and Science, 48(1), 45-75.

Parfit, Derek (1971). Personal Identity. The Philosophical Review, 8o(1), 3-27.

Parham, Peter (2015). The Immune System (Vol. 4). Garland Science.

Perry, John (Ed.) (1975). Personal Identity. University of California Press.

Popper, K (1953). The Principle of Individuation. Proceedings of the Aristotelian Society, Suppl. Vol. 27, 97-120.

Rosen, Jacob (2014). Essence and End in Aristotle. Oxford Studies in Ancient 
Philosophy, 46, 73-107.

Ross, W. D. (1924). Aristotle's Metaphysics. Clarendon Press.

Sedley, David (1982). The Stoic Criterion of Identity. Phronesis, 27(3), 255-275.

Shoemaker, Sydney (1969). Time without Change. Journal of Philosophy, 66(12), 363381 .

Shoemaker, Sydney and Swinburne, Richard (1984). Personal Identity. Blackwell.

Waterlow, Sarah (1982). Nature, Change, and Agency in Aristotle's Physics. Clarendon Press.

Whiting, Jennifer E. (1984). Individual Forms in Aristotle (Unpublished doctoral dissertation). Cornell University

Whiting, Jennifer E. (1986). Form and Individuation in Aristotle. History of Philosophy Quarterly, 3(4), 359-377.

Wiggins, David (1967). Identity and Spatio-Temporal Continuity. Basil Blackwell.

Wiggins, David (2001). Sameness and Substance Renewed. Cambridge University Press.

Williamson, Timothy (1990). Identity and Discrimination. Basil Blackwell.

Zeller, Eduard (1897). Aristotle and the Earlier Peripatetics. Longmans, Green, and Co. 